\title{
BMJ Open Multimorbidity and healthcare utilisation among high-cost patients in the US Veterans Affairs Health Care System
}

\author{
Donna M Zulman, ${ }^{1,2}$ Christine Pal Chee, ${ }^{1,3}$ Todd $\mathrm{H}$ Wagner, ${ }^{1,3,4}$ Jean Yoon, ${ }^{1,3}$ \\ Danielle M Cohen, ${ }^{2}$ Tyson H Holmes, ${ }^{5}$ Christine Ritchie, ${ }^{6,7}$ Steven M Asch ${ }^{1,2}$
}

To cite: Zulman DM,

Pal Chee C, Wagner TH, et al. Multimorbidity and healthcare utilisation among high-cost patients in the US Veterans Affairs Health Care System. BMJ Open 2015;5:e007771. doi:10.1136/bmjopen-2015007771

- Prepublication history and additional material is available. To view please visit the journal (http://dx.doi.org/ 10.1136/bmjopen-2015007771).

Received 23 January 2015 Revised 12 March 2015 Accepted 18 March 2015

CrossMark

For numbered affiliations see end of article.

Correspondence to Dr Donna M Zulman; dzulman@stanford.edu

\section{ABSTRACT}

Objectives: To investigate the relationship between multimorbidity and healthcare utilisation patterns among the highest cost patients in a large, integrated healthcare system.

Design: In this retrospective cross-sectional study of all patients in the U.S. Veterans Affairs (VA) Health Care System, we aggregated costs of individuals' outpatient and inpatient care, pharmacy services and VA-sponsored contract care received in 2010. We assessed chronic condition prevalence, multimorbidity as measured by comorbidity count, and multisystem multimorbidity (number of body systems affected by chronic conditions) among the $5 \%$ highest cost patients. Using multivariate regression, we examined the association between multimorbidity and healthcare utilisation and costs, adjusting for age, sex, race/ethnicity, marital status, homelessness and health insurance status.

Setting: USA VA Health Care System.

Participants: 5.2 million VA patients.

Measures: Annual total costs; absolute and share of costs generated through outpatient, inpatient, pharmacy and VA-sponsored contract care; number of visits to primary, specialty and mental healthcare; number of emergency department visits and hospitalisations.

Results: The 5\% highest cost patients ( $n=261699)$ accounted for $47 \%$ of total VA costs. Approximately twothirds of these patients had chronic conditions affecting $\geq 3$ body systems. Patients with cancer and schizophrenia were less likely to have documented comorbid conditions than other high-cost patients. Multimorbidity was generally associated with greater outpatient and inpatient utilisation. However, increased multisystem multimorbidity was associated with a higher outpatient share of total costs (1.6 percentage points per affected body system, $p<0.01$ ) but a lower inpatient share of total costs $(-0.6$ percentage points per affected body system, $\mathrm{p}<0.01$ ).

Conclusions: Multisystem multimorbidity is common among high-cost VA patients. While some patients might benefit from disease-specific programmes, for most patients with multimorbidity there is a need for interventions that coordinate and maximise efficiency of outpatient services across multiple conditions.

\section{Strengths and limitations of this study}

- This study describes rates of 33 chronic conditions and condition combinations, and associated utilisation and cost patterns, among the $5 \%$ highest cost patients in a large nationwide US healthcare system.

- Multimorbidity was examined using chronic condition counts and a clinical construct that incorporated conditions involving multiple body systems/specialties.

- Chronic condition and utilisation data were drawn from a single year; longitudinal patterns were not evaluated.

\section{INTRODUCTION}

Across a range of healthcare settings and populations, a small number of patients account for disproportionate costs. Within the USA, $5 \%$ of the population accounts for approximately half of the healthcare spending, ${ }^{1}$ and similar patterns have been observed among patients covered by Medicare and Medicaid. ${ }^{2} 3$ Approximately $20-60 \%$ of these individuals remain in the highest cost categories in the following year. $^{4-6}$ Given the pressing demands to contain escalating healthcare costs, many healthcare systems seek to understand and address the needs of these patients. ${ }^{7}$

Previous evaluations of high-cost patients have identified a high prevalence of common chronic conditions such as diabetes, asthma and hypertension, as well as disproportionate rates of complex and severe conditions such as heart failure and cancer. ${ }^{2}{ }^{6}$ Mental health conditions are also observed at increased rates among these patients. ${ }^{2} \quad 6 \quad 8$ However, while it is widely appreciated that many high-cost patients have multiple chronic conditions, ${ }^{19}$ little is known about the association between 
multimorbidity and healthcare utilisation patterns among these individuals. In the general population, multiple chronic conditions have been associated with increased rates of hospitalisations and physician visits, ${ }^{10}$ but these relationships have not been investigated among high-cost patients.

Understanding high-cost patients' chronic condition patterns and associated healthcare needs is likely to be of particular interest within healthcare systems that are accountable for high-risk patients. In order to inform programme development, we sought to investigate chronic conditions, multimorbidity patterns and utilisation of services among individuals with high costs in a single year in the Veterans Affairs (VA) Health Care System, the largest integrated healthcare system in the USA. Our objectives were to: (1) characterise the VA's 5\% highest cost patients over a 1-year period in terms of their chronic conditions and multimorbidity patterns and (2) determine the associations between multimorbidity and healthcare utilisation and costs among these patients.

\section{METHODS}

\section{Population and data sources}

The VA Health Care System serves close to six million veterans of the US military per year through 150 medical centres and 820 community-based outpatient clinics. The VA is considered a leader in the delivery of high-quality care in the USA. ${ }^{11}{ }^{12}$ Patients in the VA are predominantly male and typically have higher rates of physical and mental illness, and are poorer, than agematched non-Veterans. In addition, younger Veterans (individuals deployed after 9/11) have high rates of physical and emotional trauma, including post-traumatic stress disorder. Patients are eligible not only for health benefits, but also for substantial social support including disability payments, pensions, educational benefits, housing support and vocational rehabilitation.

For this cross-sectional study, we used VA medical data files to identify 5233994 patients who received any inpatient or outpatient VA care during fiscal year 2010 (1 October 2009 to 30 September 2010). We calculated the total cost of VA care for each patient, aggregating costs of inpatient, outpatient, pharmacy and VA-sponsored contract care (non-VA inpatient and outpatient services that are covered by the VA). Since there are no billing records in the VA, we used 2010 Average Costs data files to obtain cost estimates for inpatient and outpatient care based on non-VA relative value weights. ${ }^{13-15}$ We used 2010 Decision Support System pharmacy files to obtain costs of prescription drugs filled in the VA, and 2010 Fee Basis files to obtain service-specific payments made to non-VA providers for contract care.

\section{Patient characteristics}

Chronic conditions and sociodemographics

For all patients, we identified the presence of 33 chronic conditions that have been the focus of previous quality improvement efforts and research within the VA due to their prevalence, management challenges and/or $\cos ^{16-19}$ (see online supplementary appendix table 1 ). We restricted our determination to conditions that were documented by ICD-9 codes at least twice across different inpatient or outpatient encounters to avoid unconfirmed or rule-out diagnoses. We also obtained sociodemographic characteristics, including age, sex, race/ethnicity, marital status and documented homelessness during the year of investigation. Missing data were categorised as unknown and occurred at rates less than $10 \%$ for all variables. We categorised patients based on their non-VA health insurance status as having no outside medical insurance, having Medicare and/or Medicare supplemental coverage, or having other private or public insurance.

\section{Multimorbidity measures}

We assessed multisystem multimorbidity by grouping chronic conditions into body systems using an algorithm established by the Agency for Healthcare Research and Quality. ${ }^{20}$ We used this as the primary multimorbidity measure in analyses to account for the possibility that healthcare utilisation patterns may be influenced less by the number of specific conditions than by the number of different specialists and different diagnostic and treatment modalities that are required for chronic disease management. In sensitivity analyses, we also measured multimorbidity using a count of chronic conditions listed in online supplementary appendix table 1. Both multimorbidity measures were analysed as ordered categorical variables in regression models.

\section{Healthcare costs and utilisation}

For each patient, we calculated the total cost of care and the share of costs generated through inpatient, outpatient, pharmacy and VA-sponsored contract care using the data sources and estimation methods described above. ${ }^{13-15}$ We also determined the number of primary, medical specialty and mental healthcare visits, emergency department visits, and admissions for medical, surgical or mental healthcare, categorising encounters by clinic identifier codes (for outpatient utilisation) and treating specialty codes that indicate location of care (for inpatient utilisation).

\section{Analyses}

We categorised patients as high cost if their total costs of care were among the top $5 \%$ for all patients assessed. We used $\chi^{2}$ and $t$ tests in bivariate analyses to compare high-cost patients with individuals in the remaining population on the basis of sociodemographic characteristics, chronic conditions and multimorbidity prevalence, using an a priori significance level of $\mathrm{p}<0.01$ to adjust for multiple comparisons.

\section{Multimorbidity patterns}

We explored patterns of multimorbidity in several ways. First, we compared the chronic condition prevalence, 
number of chronic conditions and number of body systems affected by chronic conditions (multisystem multimorbidity) among high-cost patients and the remaining patient population. Next, we examined multisystem multimorbidity patterns by identifying body system dyads affected by chronic conditions and comparing the relative prevalence of dyads among high-cost patients and all other patients. We also coded chronic condition triads, as described in previously published studies of VA patient populations. ${ }^{19} 21$ All coded conditions were searched for all patients and all existing trios of comorbid conditions were identified. The quantity of high-cost patients with each of these identified trios was tabulated to determine the trios that were present in at least $5 \%$ of patients. Finally, we explored variations in multimorbidity rates among patients with the five most common medical conditions and the five most common mental health conditions.

\section{Association between multimorbidity and healthcare utilisation and cost}

Using multivariate regression, we examined the relationship between multisystem multimorbidity and (1) total annual healthcare costs, (2) absolute and share of total costs generated through outpatient, inpatient and pharmacy care and (3) number of primary, specialty and mental healthcare visits, emergency department visits, and hospitalisations over the year of investigation. All regressions adjusted for patient age, sex, race/ethnicity, marital status, documented homelessness during the year of investigation, health insurance status and correlation within facilities. In sensitivity analyses, we repeated regressions substituting comorbidity count for multisystem multimorbidity. We also repeated regressions after excluding individuals who died in the year of investigation, to determine whether findings were influenced by end-of-life utilisation and costs.

To examine differences in absolute costs (total and specific categories), we utilised ordinary least squares regression. To examine differences in the share of costs generated through inpatient care, outpatient care and pharmacy care, we used fractional logit regression. ${ }^{22}$ Finally, to evaluate differences in utilisation (count variables with excess zeros), we used zero-inflated negative binomial regression and zero-inflated Poisson regression, and we report findings for the models with best fit. For each model, we present predicted values of the outcome for each level of multimorbidity, holding other covariates at their mean value in order to illustrate the effect of multimorbidity on the outcome of interest. We also present the average difference across multimorbidity groups, which represents the average predicted change in the dependent variable (absolute cost, share of total cost or utilisation count, respectively) per each additional body system affected by chronic conditions. Average differences are estimates, via unweighted ordinary least squares, of the slope of a linear regression of cost on multimorbidity count, where body system counts of seven and greater were coded as seven. Statistical significance was calculated using estimated coefficients and SEs from the regressions. We explored alternative regression models, including linear regression for all analyses, to ensure optimal fit of our selected models.

We used Stata V.12.0 (StataCorp 2011, College Station, Texas, USA) to perform all analyses. Analyses used de-identified data and were approved by the Stanford University Institutional Review Board.

\section{RESULTS}

High-cost patients ( $\mathrm{n}=261699$ ) accounted for $47 \%$ of total VA costs in 2010. In aggregate, inpatient care accounted for $50 \%$ of costs, outpatient care for $32 \%$ of costs, and pharmacy and VA-sponsored contract care for $8 \%$ and $10 \%$ of costs, respectively. Table 1 describes healthcare costs and sociodemographic characteristics for high-cost patients compared with the remaining $95 \%$ of VA patients (table 2).

\section{Chronic conditions and multimorbidity patterns}

Chronic condition prevalence was greater among highcost patients than among the remaining $95 \%$ of patients for all specific conditions assessed (see online supplementary appendix table 1 ). The most common chronic conditions among high-cost patients included hypertension $(63 \%)$, diabetes (34\%), depression (29\%) and ischaemic heart disease $(27 \%)$. One in four patients (25\%) had a diagnosis of cancer, and close to half $(48 \%)$ of high-cost patients had a diagnosed mental health condition.

Multimorbidity was extremely common among highcost patients, with $77 \%$ and $41 \%$ having $\geq 3$ and $\geq 5$ chronic conditions, respectively, and $64 \%$ and $18 \%$ having $\geq 3$ and $\geq 5$ body systems affected by chronic conditions, respectively (table 1). Multisystem multimorbidity most commonly involved circulatory conditions paired with endocrine conditions $(34 \%)$, mental health conditions (32\%) and musculoskeletal conditions (25\%). Mental health conditions also frequently co-occurred with musculoskeletal conditions $(20 \%)$ and endocrine conditions (17\%) (figure 1). The most prevalent triads of specific chronic conditions are listed in online supplementary appendix table 2.

Figure 2 illustrates multimorbidity rates among patients with the five most common medical and five most common mental health conditions. For the majority of specified conditions, as many as two-thirds of affected patients had $\geq 5$ total comorbidities. For certain conditions, however, such as cancer and schizophrenia, fewer than half of the affected patients had this level of multimorbidity. Among patients with cancer and schizophrenia, 22\% and $18 \%$ had no more than one comorbid condition, respectively. In contrast, among patients with all other conditions listed, only $5-11 \%$ of affected patients had no more than one comorbid condition. 
Table 1 Characteristics of the $5 \%$ highest cost patients compared with the remaining population receiving VA care in 2010

\begin{tabular}{|c|c|c|}
\hline & $\begin{array}{l}\text { High-cost patients* } \\
\mathrm{n}=261699 \\
\% \neq\end{array}$ & $\begin{array}{l}\text { Remaining populationt } \\
n=4972295 \\
\% \neq\end{array}$ \\
\hline Age, mean (SD) & $63(13)$ & $63(16)$ \\
\hline$<45$ & 7 & 14 \\
\hline $45-64$ & 52 & 41 \\
\hline $65+$ & 41 & 45 \\
\hline Male sex & 95 & 93 \\
\hline \multicolumn{3}{|l|}{ Race/ethnicity } \\
\hline White, non-hispanic & 70 & 72 \\
\hline Black, non-hispanic & 21 & 14 \\
\hline Hispanic & 6 & 5 \\
\hline Other & 2 & 2 \\
\hline Unknown & 2 & 8 \\
\hline \multicolumn{3}{|l|}{ Marital status } \\
\hline Single & 14 & 12 \\
\hline Married & 41 & 58 \\
\hline Separated/divorced/widowed & 45 & 30 \\
\hline Homeless during year of study & 14 & 2 \\
\hline \multicolumn{3}{|l|}{ Insurance status } \\
\hline None & 46 & 41 \\
\hline Major medical/HMO/PPO/champus/indemnity & 8 & 18 \\
\hline Medicare/Medicare supplement & 44 & 39 \\
\hline All other & 2 & 2 \\
\hline Died during year of study & 11 & 2 \\
\hline \multicolumn{3}{|l|}{ Multimorbidity } \\
\hline$\geq 3$ Chronic conditions & 77 & 26 \\
\hline$\geq 5$ Chronic conditions & 41 & 7 \\
\hline$\geq 3$ Body systems affected by conditions & 64 & 19 \\
\hline$\geq 5$ Body systems affected by conditions & 18 & 2 \\
\hline \multicolumn{3}{|l|}{ Annual healthcare costs, mean (SD), median } \\
\hline Total & 72976 (64 040), 52807 & 4267 (5252), 2257 \\
\hline Inpatient care & 42179 (58 679), 26979 & $398(2167), 0$ \\
\hline Outpatient care & 19182 (30 269), 12699 & 2840 (3433), 1566 \\
\hline Pharmacy services & 4525 (13 141), 1738 & 812 (1499), 337 \\
\hline VA-sponsored contract care & 7090 (20 490), 0 & 213 (1258), 0 \\
\hline
\end{tabular}

*High-cost patients represent the $5 \%$ highest cost patients who received inpatient or outpatient care in the VA healthcare system between 1 October 2009 and 30 September 2010. Numbers represent percentages within each category unless otherwise indicated.

tp Values for $t$ tests (mean age, costs) and $\chi^{2}$ tests (all other characteristics) were $<0.001$ for all comparisons between high-cost patients and the remaining population.

fUnless otherwise specified.

HMO, Health Maintenance Organization; PPO, Preferred Provider Organization; VA, Veterans Affairs.

\section{Association between multimorbidity and healthcare utilisation and costs}

Among high-cost patients, there was a positive association between multimorbidity and healthcare costs, with an average increase of $\$ 1774$ in total costs for each body system affected by chronic conditions $(\mathrm{p}<0.01)$. However, the association between multisystem multimorbidity and costs varied for outpatient versus inpatient care. For outpatient care, each additional body system affected by chronic conditions was associated with an average increase of $\$ 1444$ in outpatient costs, which translated to a 1.6 percentage point increase in outpatient share of total costs $(p<0.01)$. In contrast, for inpatient care, each additional body system affected by chronic conditions was associated with an average increase of $\$ 577$ in inpatient costs, but this translated to a 0.6 percentage point decrease in inpatient share of total costs $(p<0.01)$. Patterns did not change markedly after excluding individuals who died in the year of investigation (see online supplementary appendix table 3 ).

Sensitivity analyses examining cost differences by number of specific chronic conditions rather than by number of affected body systems can be found in online supplementary appendix table 4 . While the positive and strong association between multimorbidity and predicted share of outpatient costs was unchanged, higher chronic condition counts were associated with a small but statistically significant increase in inpatient share of total cost and a decrease in the share of costs attributed to pharmacy. These findings are most likely related to the high 
Table 2 Relationship between multimorbidity and absolute $\dagger$ and share $\ddagger$ of total costs generated through inpatient, outpatient and pharmacy care among high-cost VA patients

\begin{tabular}{|c|c|c|c|c|c|c|c|c|}
\hline \multirow{2}{*}{$\begin{array}{l}\text { Number of } \\
\text { body systems } \\
\text { affected by } \\
\text { chronic } \\
\text { conditions }\end{array}$} & \multirow[b]{2}{*}{$\mathbf{n}$} & \multirow{2}{*}{$\begin{array}{l}\text { Total§ } \\
\begin{array}{l}\text { Predicted } \\
\text { costs }\end{array}\end{array}$} & \multicolumn{2}{|l|}{ Inpatient } & \multicolumn{2}{|l|}{ Outpatient } & \multicolumn{2}{|l|}{ Pharmacy } \\
\hline & & & $\begin{array}{l}\text { Predicted } \\
\text { costs }\end{array}$ & $\begin{array}{l}\text { Predicted } \\
\text { share of } \\
\text { total }\end{array}$ & $\begin{array}{l}\text { Predicted } \\
\text { costs }\end{array}$ & $\begin{array}{l}\text { Predicted } \\
\text { share of } \\
\text { total }\end{array}$ & $\begin{array}{l}\text { Predicted } \\
\text { costs }\end{array}$ & $\begin{array}{l}\text { Predicted } \\
\text { share of } \\
\text { total }\end{array}$ \\
\hline 1 & 30772 & 70671 & 41531 & 50.7 & 16196 & 28.0 & 4468 & 7.5 \\
\hline 2 & 54837 & 69342 & 40183 & 51.3 & 17883 & 30.3 & 4280 & 7.2 \\
\hline 3 & 66610 & 71010 & 40403 & 50.5 & 19395 & 32.0 & & \\
\hline 4 & 53937 & 73455 & 41481 & 49. & 20879 & 33. & 4613 & 7. \\
\hline 5 & 30509 & 75455 & 42466 & 49.1 & 22034 & 34.8 & 5001 & 7.9 \\
\hline 6 & 12566 & 78807 & 44089 & 48.3 & 23448 & 35.8 & 5340 & 8.3 \\
\hline $7+$ & 4419 & 81544 & 44994 & 47.4 & 24938 & 36.9 & 5952 & 8.7 \\
\hline $\begin{array}{l}\text { Average } \\
\text { differenceף }\end{array}$ & & $1774^{*}$ & $577^{*}$ & $-0.6^{*}$ & $1444^{*}$ & $1.6^{\star}$ & $199^{*}$ & $0.2^{*}$ \\
\hline \multicolumn{9}{|c|}{$\begin{array}{l}\text { * } p<0.01 . \\
\text { fPredicted absolute costs are generated via multivariate linear regression examining associations between number of body systems affected } \\
\text { by chronic conditions and costs, adjusting for age, sex, race/ethnicity, marital status, homelessness and insurance status. } \\
\text { †Predicted shares of total cost are generated via fractional logit regression examining associations between the number of body systems } \\
\text { affected by chronic conditions and shares of total cost within each domain of care, adjusting for age, sex, race/ethnicity, marital status, } \\
\text { homelessness and insurance status. } \\
\text { §Component costs and cost shares sum approximately to total when VA-sponsored contract care (omitted for clarity) is included. Note that } \\
\text { dividing predicted component costs by predicted total costs does not equal the predicted share of total. The former is a ratio of means and the } \\
\text { latter is a mean of ratios, and although both procedures estimate the same quantity, they are not guaranteed to produce the same result. The } \\
\text { two procedures do, however, produce comparable results. } \\
\text { १Average differences represent change in costs (for absolute costs) or percentage point change in share of cost (for share of total cost } \\
\text { generated within each domain of cost) for each additional body system affected by chronic conditions. }\end{array}$} \\
\hline
\end{tabular}

rates of cancer and schizophrenia among patients with one condition, as both of these diseases are associated with frequent inpatient utilisation and many cancer medications are extremely costly.

Multisystem multimorbidity was associated with an increase in utilisation of most healthcare services (table 3). Each additional body system affected by chronic conditions was associated with an average increase of 0.2 hospitalisations and 0.4 emergency department visits, as well as an average increase of 1.5 primary care visits and 0.7 specialty care visits. All associations between multisystem multimorbidity and these utilisation categories were significant at $\mathrm{p}<0.01$. No association was detected between multisystem multimorbidity and number of mental healthcare visits when all patients were included in analyses. However, among the subgroup of patients with a mental health diagnosis $(\mathrm{n}=125962)$, there was a decrease in 1.9 mental healthcare visits per each body system affected by chronic conditions $(\mathrm{p}<0.01)$.

\section{DISCUSSION}

The 5\% highest cost patients in the US VA Health Care System in 2010 accounted for approximately half of the total healthcare spending. Multimorbidity is common among these patients, and approximately two-thirds have chronic conditions affecting three or more body systems. We observed a number of multimorbidity patterns and associated healthcare utilisation trends that may inform healthcare delivery models for complex, high-cost patients.
First, our findings suggest that programmes for highcost patients need to address individuals' challenges across multiple conditions. Several systematic reviews and guidelines have described strategies to improve care for patients with multimorbidity, for example through specialty care coordination, medication reconciliation, self-management support, and elimination of redundant testing and services. ${ }^{23-25}$ Recent reviews of primary care interventions and guidelines for managing multiple chronic conditions have also emphasised the importance of considering patient preferences, functional difficulties and prognosis when developing care plans. ${ }^{23}{ }^{25}$ By incorporating these strategies, intensive primary care programmes could potentially reduce the volume and burden of healthcare for high-cost patients with multiple chronic conditions.

Second, while programmes for high-risk, high-cost patients frequently concentrate on preventing hospitalisation and reducing length of stay, ${ }^{26} 27$ our findings suggest that high-cost patients with multiple chronic conditions may also benefit from attention to the appropriateness of outpatient services. We found that greater multisystem multimorbidity was associated with marked increases in outpatient services and a higher share of costs generated in the outpatient setting, and a lower share of costs generated in the inpatient setting.

These findings contribute to a growing body of literature that aims to inform healthcare delivery models for high-cost patients. Recently, a study published in JAMA determined that among high-cost Medicare patients, only a small percentage of costs from hospitalisation and 


\section{Circ}

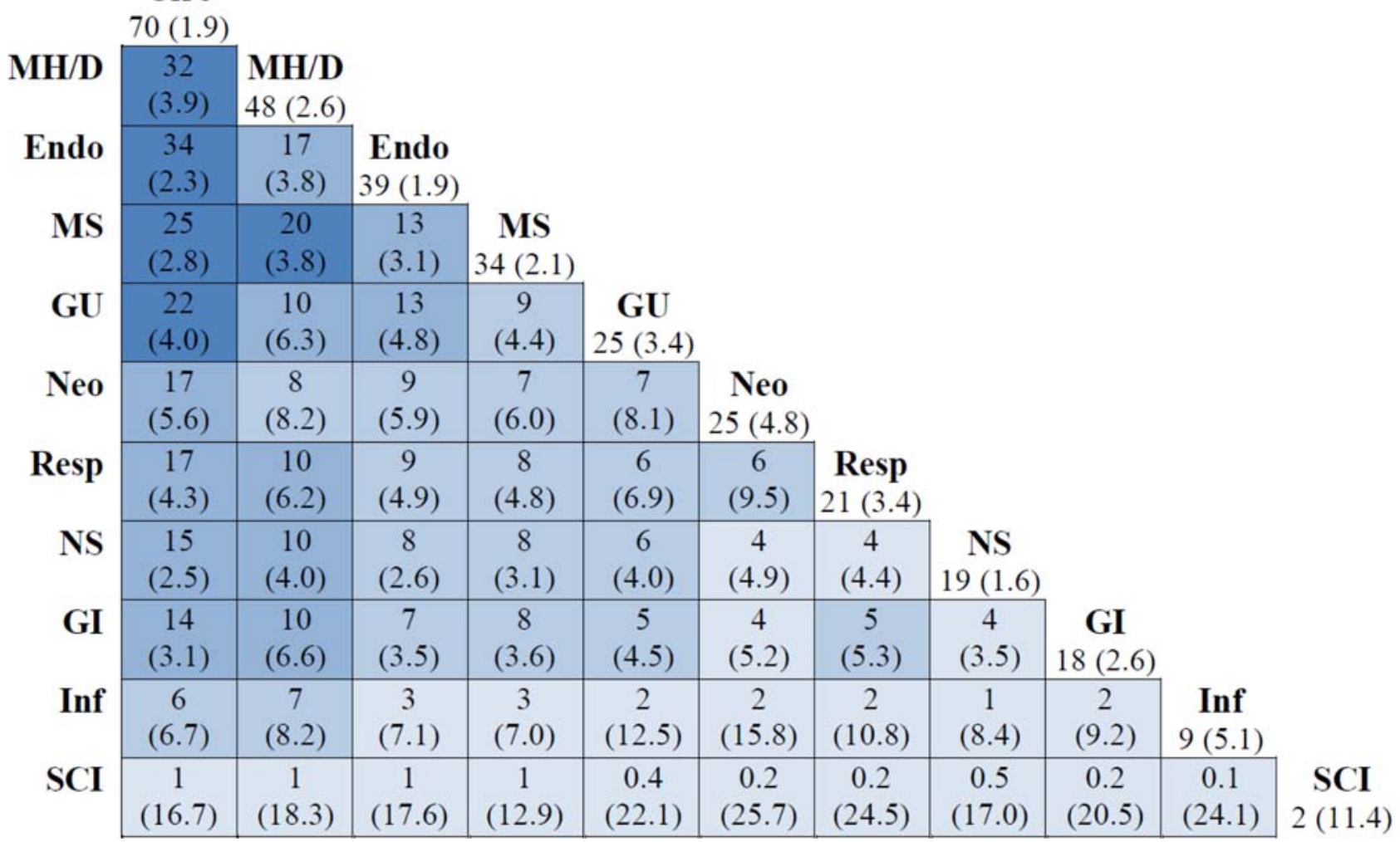

Figure 1 Prevalence of body systems affected by chronic conditions and multisystem multimorbidity among high-cost VA patients (relative to remaining $95 \%$ of patients). Numbers at the top of each column represent the percentage of high-cost patients with one or more chronic conditions affecting the specified body system. Numbers within each cell represent the percentage of high-cost patients with chronic conditions affecting the dyad of body systems on both horizontal and vertical axes. Numbers in parentheses represent the relative prevalence when comparing high-cost patients with the remaining population. Shades highlight different prevalence levels, with darker shades representing higher rates $(<5 \%, 5-9 \%, 10-19 \%$ and $\geq 20 \%$, respectively). For the prevalence and relative prevalence of specific chronic conditions, see online supplementary appendix table 1. Circ, circulatory; Endo, endocrine; GI, gastrointestinal; GU, genitourinary; Inf, infectious; MH/D, Mental Health and Dementia; MS, musculoskeletal; Neo, neoplasm; NS, nervous system/sense organs; Resp, respiratory; SCl, spinal cord injury; VA, Veterans Affairs.

emergency department visits were related to health deteriorations that may have been prevented through highquality primary care. The authors concluded that it will be challenging to lower costs for these patients through better outpatient care. ${ }^{2}$ However, we found that outpatient care was a major contributor to costs in high-cost VA patients, especially among patients with high levels of multimorbidity, suggesting that at least among a subset of high-cost patients there may be an opportunity to influence total cost through highly coordinated and efficient services in the outpatient setting.

Third, our findings suggest a need for strategies that address high-cost patients' mental health. Close to half of our study population had a mental health diagnosis, and similarly high rates have been observed among high-cost Medicaid patients. ${ }^{8}$ In VA and Medicaid highcost patients, mental health diagnoses frequently co-occur with cardiovascular, endocrine and musculoskeletal conditions-conditions for which there is substantial literature describing increased risk and higher utilisation when comorbid mental illness is present. ${ }^{28-32}$ Interestingly, among patients in our sample who had a mental health diagnosis, frequency of outpatient mental healthcare was inversely correlated with greater multisystem multimorbidity. This finding may be driven by patients with serious mental illness and low multimorbidity who incur high costs through their frequent use of mental health services. However, another potential explanation is that patients with multiple chronic conditions may be overwhelmed and saturated with care and do not receive the intensity of mental healthcare that they need. This latter scenario would support a role for integrated care models that address comorbid mental illness together with complex and costly medical conditions.

Finally, this study highlights the heterogeneity of patients with high costs, and suggests that a one-size-fits-all intervention may not be the optimal approach. The evidence base for intensive interventions is still limited, and important questions remain about how best to identify patients and match services to their needs. There may be individuals with stable chronic conditions and strong social support who are unlikely to benefit substantially from intensive management 


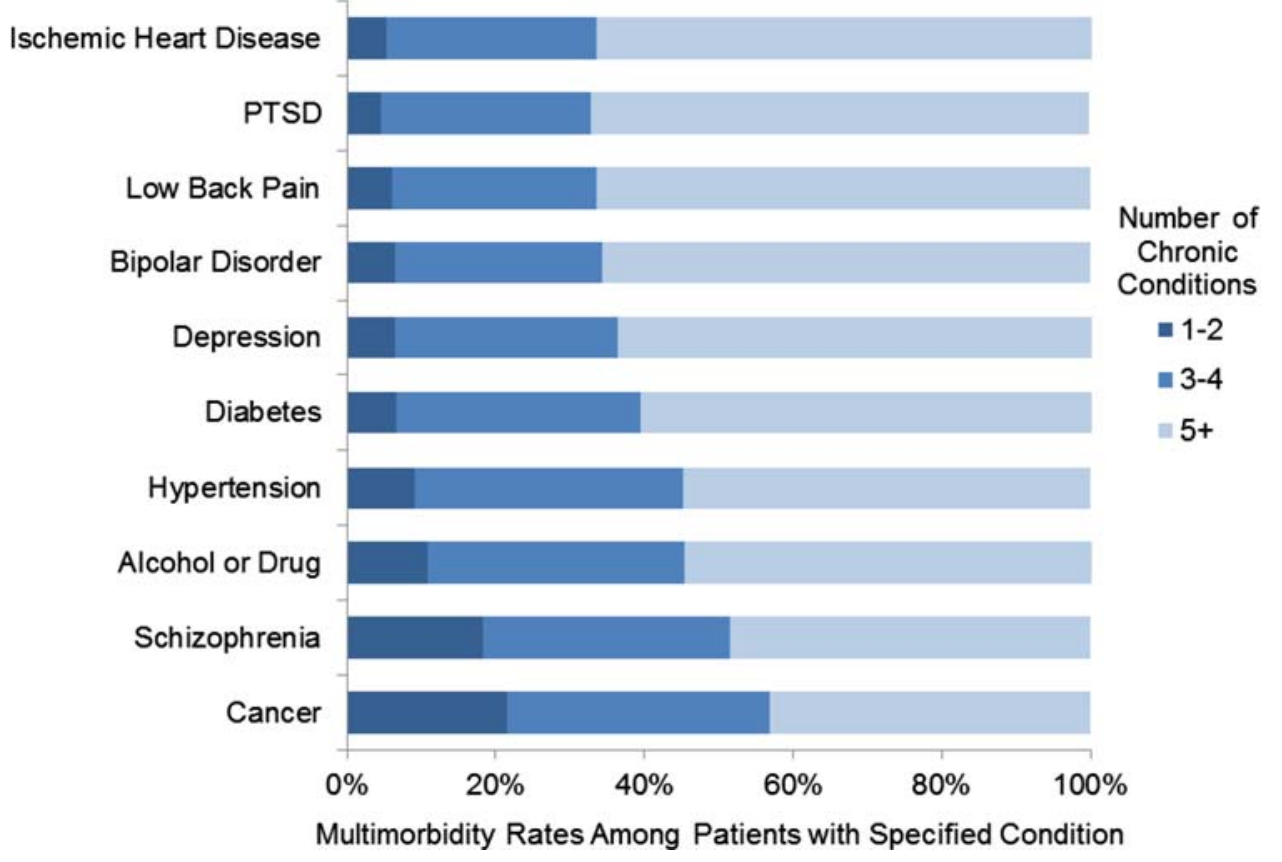

Figure 2 Variation in number of comorbidities among high-cost Veterans Affairs (VA) patients with common medical and mental health conditions (PTSD, post-traumatic stress disorder).

programmes. Other patients may have highly specialised needs. For example, while the majority of high-cost patients in our study had multiple chronic conditions, we identified subgroups of patients with cancer and schizophrenia who have lower levels of multimorbidity. This finding is notable because intensive primary care programmes that are focused on coordinating care for multiple chronic conditions may not be the best fit for patients whose care needs are dominated by these types of conditions. Health systems may instead choose to ensure that high-cost patients who have cancer or a serious mental illness but few comorbidities receive care within multidisciplinary programmes that are focused on these diseases.

These analyses are limited by several factors. First, our findings reflect patterns observed among patients who were identified as high cost over a 1-year period, and might not be generalisable to the $20-60 \%$ of high-cost patients who persist in this category over 2 years. ${ }^{4-6}$ Second, there is little consensus about how best to define multimorbidity and how to categorise conditions in studies of multimorbidity. We attempted to address this by examining both comorbidity counts and multisystem multimorbidity (the latter of which may better

Table 3 Relationship between multisystem multimorbidity and mean annual healthcare utilisation† among high-cost VA patients

\begin{tabular}{|c|c|c|c|c|c|c|}
\hline $\begin{array}{l}\text { Number of body systems affected } \\
\text { by chronic conditions }\end{array}$ & $\mathbf{n}$ & $\begin{array}{l}\text { Primary } \\
\text { care visits }\end{array}$ & $\begin{array}{l}\text { Specialty } \\
\text { care visits }\end{array}$ & $\begin{array}{l}\text { Mental health } \\
\text { visitsł }\end{array}$ & $\begin{array}{l}\text { Emergency } \\
\text { visits }\end{array}$ & $\begin{array}{l}\text { Hospital } \\
\text { admissions }\end{array}$ \\
\hline 1 & 30772 & 3.1 & 3.0 & 15.4 & 1.2 & 1.0 \\
\hline 2 & 54837 & 4.5 & 3.7 & 14.9 & 1.6 & 1.3 \\
\hline 3 & 66610 & 5.6 & 4.4 & 14.5 & 1.9 & 1.5 \\
\hline 4 & 53937 & 6.7 & 5.2 & 14.1 & 2.3 & 1.8 \\
\hline 5 & 30509 & 7.8 & 5.9 & 14.6 & 2.8 & 2.0 \\
\hline 6 & 12566 & 9.1 & 6.7 & 14.2 & 3.4 & 2.3 \\
\hline $7+$ & 4419 & 10.5 & 7.7 & 15.1 & 4.0 & 2.6 \\
\hline Average difference§ & & $1.5^{\star}$ & $0.7^{\star}$ & -0.2 & $0.4^{*}$ & $0.2^{*}$ \\
\hline
\end{tabular}

${ }^{*} \mathrm{p}<0.01$.

†Predicted annual utilisation rates are generated via multivariate zero-inflated negative binomial regression (for outpatient utilisation) and zero-inflated Poisson regression (for hospital admissions) examining associations between number of systems affected by chronic conditions and utilisation within each domain. All regressions adjust for age, sex, race/ethnicity, marital status, homelessness and insurance status. ¥Among patients with a mental health diagnosis $(n=125$ 962), predicted mental healthcare visits decreased from 32.3 to 20.9 among patients with 1 versus $\geq 7$ body systems affected by chronic conditions, respectively, with an average decrease in 1.9 visits per body system affected by chronic conditions $(p<0.01)$.

$\S$ Average differences represent change in annual utilisation for each additional system affected by chronic conditions. 
reflect patients' requirements for different specialists and services ${ }^{33}$ ). Third, we chose to limit our analyses to 33 chronic conditions that have been the focus of previous studies within the VA because of their prevalence, management challenges and/or cost. $^{16}$ While not exhaustive, we feel that this list represents the most common, complex and costly conditions across a range of body systems. Fourth, the VA does not routinely bill for healthcare services, so we used cost estimates based on non-VA relative value weights ${ }^{13}{ }^{14}$ which compare favourably to activity-based costing methods without needing to adjust for local input prices. ${ }^{34}$

In addition, observed chronic condition (and multimorbidity) prevalence may be influenced by coding accuracy. Certain conditions, such as dementia, are frequently under-coded, ${ }^{35}$ and comorbidity under-coding may occur more frequently in a patient with a severe and complicated condition such as cancer or serious mental illness. VA providers are not incentivised to assiduously code conditions in the way that providers in Medicare Managed Care are, which could lead to undercoding. We also used a fairly stringent coding definition based on ICD-9 diagnoses being present at least twice in inpatient or outpatient records. However, previous assessments have found that using more restrictive coding definitions can reduce the observed prevalence of individual conditions but does not change their rank order in a meaningful way. ${ }^{21}$ Finally, the relationships that we observed may be limited to the VA population; however, the VA is a very large healthcare system and its patients' high rates of physical and psychosocial health problems are similar to those observed in safety net systems worldwide.

In conclusion, our analyses of high-cost patients in the VA healthcare system suggest that while certain individuals such as some patients with cancer or serious mental illness may benefit from disease-specific interventions, the majority most likely require programmes that address their heterogeneous health needs. As multimorbidity affects a greater number of body systems, patients incur a higher share of their costs as outpatients, suggesting a role for intensive primary care programmes that coordinate specialty care and eliminate redundant testing and unnecessary visits. In order to achieve maximal value, these programmes should ensure that their focus extends beyond preventing hospitalisation and should identify opportunities to reduce the volume and burden of outpatient care for patients with multiple chronic conditions.

\footnotetext{
Author affiliations

${ }^{1}$ Center for Innovation to Implementation, VA Palo Alto Health Care System, Menlo Park, California, USA

${ }^{2}$ Division of General Medical Disciplines, Stanford University, Stanford, California, USA

${ }^{3}$ Health Economics Resource Center, VA Palo Alto Health Care System, Menlo Park, California, USA

${ }^{4}$ Health Research and Policy, Stanford University, Stanford, California, USA

${ }^{5}$ Department of Psychiatry and Behavioral Sciences, Stanford University,

Stanford, California, USA
}

${ }^{6}$ Division of Geriatrics, University of California, San Francisco, California, USA ${ }^{7}$ San Francisco VA Medical Center, San Francisco, California, USA

Acknowledgements The authors thank Jennifer Yang Scott for her assistance in database development and management.

Contributors DMZ conceptualised the study and wrote the article. DMZ, CPC and DMC conducted data analyses. THH provided guidance in statistical analyses. All authors contributed to the design of the study, helped interpret the findings and approved the final version of the manuscript.

Funding DMZ is supported by a U.S. Department of Veterans Affairs (VA) HSR\&D Career Development Award (CDA 12-173). CPC, THW, and JY received core funding SDR-ECN-99017-1 to the VA Health Economics Resource Center. THH and DMC are supported in part by the VA Office of Specialty Care Services (Specialty/Surgical Care Neighborhood Team Based Model Pilot Program). CR is supported by the Advanced IIIness and Multimorbidity Geriatric Academic Leadership Award (1K07AG31779).

\section{Competing interests None declared}

Provenance and peer review Not commissioned; externally peer reviewed.

Data sharing statement No additional data are available.

Open Access This is an Open Access article distributed in accordance with the Creative Commons Attribution Non Commercial (CC BY-NC 4.0) license, which permits others to distribute, remix, adapt, build upon this work noncommercially, and license their derivative works on different terms, provided the original work is properly cited and the use is non-commercial. See: http:// creativecommons.org/licenses/by-nc/4.0/

\section{REFERENCES}

1. Cohen S, Uberoi N. Differentials in the concentration in the level of health expenditures across population subgroups in the U.S., 2010. Rockville, MD: Agency for Healthcare Research and Quality Statistical Brief \#421, 2013. http://meps.ahrq.gov/mepsweb/data_ files/publications/st421/stat421.shtml (accessed 22 Jan 15).

2. Joynt K, Gawande AA, Orav E, et al. Contribution of preventable acute care spending to total spending for high-cost Medicare patients. JAMA 2013;309:2572-8.

3. Sommers A, Cohen M. Medicaid's High Cost Enrollees: How Much Do They Drive Program Spending? Washington, DC: Kaiser Commission for Medicaid and the Uninsured, 2006.

4. Garber AM, MaCurdy TE, McClellan MB. Persistence of Medicare expenditures among elderly beneficiaries. In: Garber AM, ed. Frontiers in Health Policy Research. Vol 1. Cambridge, MA: MIT, 1998:153-80.

5. Cohen S, Yu W. AHRQ Statistical Brief \#354: The concentration and persistence in the level of health expenditures over time: Estimates for the US population, 2008-2009. 2012. http://meps.ahrq.gov/mepsweb/ data_files/publications/st354/stat354.pdf (accessed 28 Nov 2012).

6. Coughlin T, Long S. Health care spending and service use among high-cost Medicaid beneficiaries, 2002-2004. Inquiry 2009;46:405-17.

7. Hasselman D. Super-Utilizer Summit: Common Themes from Innovative Complex Care Management Programs. Hamilton, $\mathrm{NJ}$ : Center for Health Care Strategies, Inc., 2013.

8. Kronick RG, Bella M, Gilmer TP, et al. The Faces of Medicaid II: recognizing the care needs of people with multiple chronic conditions. Center for Health Care Strategies, Inc., 2007.

9. Powers BW, Chaguturu SK, Ferris TG. Optimizing high-risk care management. JAMA 2015;313:795-6.

10. Centers for Medicare and Medicaid Services. Chronic Conditions among Medicare Beneficiaries. Chartbook: 2012 Edition. http://www. cms.gov/Research-Statistics-Data-and-Systems/Statistics-Trendsand-Reports/Chronic-Conditions/Downloads/2012Chartbook.pdf (accessed 2 Apr 2015)

11. Kizer KW, Dudley RA. Extreme makeover: transformation of the veterans health care system. Annu Rev Public Health 2009;30:313-39.

12. Asch SM, McGlynn EA, Hogan MM, et al. Comparison of quality of care for patients in the Veterans Health Administration and patients in a national sample. Ann Intern Med 2004;141:938-45.

13. Phibbs CS, Bhandari A, Yu W, et al. Estimating the costs of VA ambulatory care. Med Care Res Rev 2003;60(3 Suppl):54-73.

14. Wagner TH, Chen S, Barnett PG. Using average cost methods to estimate encounter-level costs for medical-surgical stays in the VA. Med Care Res Rev 2003;60(3 Suppl):15S-36S. 
15. Yu W, Wagner TH, Chen S, et al. Average cost of VA rehabilitation, mental health, and long-term hospital stays. Med Care Res Rev 2003;60(3 Suppl):40S-53S.

16. Yoon J, Scott J, Phibbs CS, et al. Recent trends in Veterans Affairs chronic condition spending. Popul Health Manag 2011;14:293-8.

17. Demakis J, McQueen L, Kizer K, et al. Quality Enhancement Research Initiative (QUERI): a collaboration between research and clinical practice. Med Care 2000;38(6 Suppl 1):117-25.

18. Yu W, Ravelo A, Wagner TH, et al. Prevalence and costs of chronic conditions in the VA health care system. Med Care Res Rev 2003;60 (3 Suppl):146S-67S.

19. Yoon J, Zulman D, Scott JY, et al. Costs associated with multimorbidity among VA patients. Med Care 2014;52(Suppl 3):S31-6.

20. Agency for Healthcare Research and Quality. HCUP Chronic Condition Indicator. Healthcare Cost and Utilization Project (HCUP). 2011. http://www.hcup-us.ahrq.gov/toolssoftware/chronic/chronic.jsp (accessed 17 Jul 2013).

21. Steinman MA, Lee SJ, Boscardin WJ, et al. Patterns of multimorbidity in elderly veterans. J Am Geriatr Soc 2012;60:1872-80.

22. Papke LE, Wooldridge JM. Econometric methods for fractional response variables with an application to $401(\mathrm{~K})$ plan participation rates. J Appl Econ 1996;11:619-32.

23. Smith $\mathrm{S}$, Soubhi $\mathrm{H}$, Fortin $\mathrm{M}$, et al. Interventions for improving outcomes in patients with multimorbidity in primary care and community settings. Cochrane Database Syst Rev 2012;4:CD006560.

24. Grant RW, Adams AS, Bayliss EA, et al. Establishing visit priorities for complex patients: a summary of the literature and conceptual model to guide innovative interventions. Healthcare 2013;1:117-22.

25. Guiding Principles for the Care of Older Adults with Multimorbidity: An Approach for Clinicians. American Geriatrics Society Expert Panel on the Care of Older Adults with Multimorbidity. J Am Geriatr Soc 2012;60:E1-25.
26. Peterson D, Helfand M, Humphrey L, et al. Evidence Brief: Effectiveness of Intensive Primary Care Programs, VA-ESP Project \#09-199. 2012.

27. Brown RS, Peikes D, Peterson G, et al. Six features of Medicare coordinated care demonstration programs that cut hospital admissions of high-risk patients. Health Affairs (Project Hope) 2012;31:1156-66.

28. Boyd C, Leff B, Weiss C, et al. Clarifying multimorbidity patterns to improve targeting and delivery of clinical services for Medicaid populations. Center for Health Care Strategies, Inc., 2010.

29. Hutter N, Schnurr A, Baumeister H. Healthcare costs in patients with diabetes mellitus and comorbid mental disorders-a systematic review. Diabetologia 2010;53:2470-9.

30. Molosankwe I, Patel A, Jose Gagliardino J, et al. Economic aspects of the association between diabetes and depression: a systematic review. J Affect Disord 2012;142(Suppl):S42-55.

31. Hutter N, Knecht A, Baumeister H. Health: care costs in persons with asthma and comorbid mental disorders: a systematic review. Gen Hosp Psychiatry 2011;33:443-53.

32. Yohannes AM, Willgoss TG, Baldwin RC, et al. Depression and anxiety in chronic heart failure and chronic obstructive pulmonary disease: prevalence, relevance, clinical implications and management principles. Int J Geriatric Psychiatry 2010;25:1209-21.

33. Medicare Payment Advisory Commission. Issues for risk adjustment in Medicare Advantage. Report to Congress: Medicare and the Health Care Delivery System. Washington, DC, 2012.

34. Chapko MK, Liu CF, Perkins M, et al. Equivalence of two healthcare costing methods: bottom-up and top-down. Health Econ 2009;18:1188-201.

35. Newcomer R, Clay T, Luxenberg JS, et al. Misclassification and selection bias when identifying Alzheimer's disease solely from Medicare claims records. J Am Geriatr Soc 1999;47:215-19. 